\title{
CATALOGANDO LA DIVERSIDAD DEL COMPORTAMIENTO HUMANO: LA NOSOLOGÍA FRANCESA DECIMONÓNICA ANTE LAS CONDUCTAS DELICTIVAS (1800-1855)"
}

\author{
José Martínez-Pérez \\ Unidad de Historia de la Medicina - Dpto. de Salud Pública e Historia de la Ciencia - U.C.M.
}

\begin{abstract}
RESUMEN
El presente trabajo tiene como objetivo contribuir al conocimiento de los factores que influyen sobre el proceso de clasificación de la diversidad del comportamiento humano. Se estudia para ello los cambios operados a comienzos del siglo XIX en el modo de catalogar una forma de conducta desviada: la homicida. La creación por los psiquiatras franceses de la categoría diagnóstica de la monomanía homicida instintiva sirvió para que ciertos tipos de homicidios dejaran de ser interpretados como delitos y empezaran a ser contemplados como formas de locura. El surgimiento y progresiva desaparición de esta especie morbosa de las clasificaciones psiquiátricas de la primera mitad del siglo XIX pone de relieve cómo la asignación de un comportamiento aberrante a un tipo u otro de desviación depende de la manera en que se relacionan diversos factores: los cambios en las teorías científicas; las permutas en los objetivos profesionales de quienes hacen las clasificaciones; y el grado de consenso social que se consigue alcanzar para el nuevo significado que adquiere la conducta desviada al cambiar su ubicación entre las diversas formas de desviación.
\end{abstract}

\section{ABSTRACT}

This work aims to contribute to the study of the factors which influenced the process of the classification of the diversity of human behaviour. As a result this study will look at the changes in operation at the beginning of the nineteenth century regarding the classification of one type of deviant behaviour: homicide. The creation by French psychiatrists of the diagnostic category "monomanie homicide instintive" meant that certain types of homicide were no longer considered a crime and began to be regarded as forms of madness. The emergence and gradual disappearance of this morbid species of psychiatric classifications in the first half of the XIX ${ }^{\text {th }}$ century illustrates how the assignation of aberrant behaviour to one kind or other of deviance depends on the way in which various factors are related: changes in scientific theories, permutations in the professional objectives of those who make the classifications, and the degree of social consensus which is achieved for

* Este trabajo ha sido realizado con cargo al proyecto $n .{ }^{\circ} \mathrm{PB}-94-0060$ de la DGICYT. 
the new meaning that the deviatory behaviour acquires on changing its position among the various forms of deviation.

\section{INTRODUCCIÓN}

Es indudable que una de las expresiones más relevantes de la diversidad de los seres humanos es la que tiene que ver con su comportamiento. La importancia que se ha concedido a la variabilidad de las conductas se expresa en el hecho de que se ha convertido en un elemento esencial del que nos servimos para, con todo lo que ello implica, caracterizarlos tanto individual como colectivamente. En relación con esto último conviene recordar que el conjunto de normas y reglas, fijadas o no en códigos de justicia, que establecen la manera en que los miembros de los diferentes grupos humanos se comportan ante determinadas situaciones de la vida social -matrimonio, relaciones sexuales... - resulta fundamental a la hora de establecer un rasgo característicos de dichos colectivos como es su cultural.

Pero el tipo de comportamiento también sirve, como hemos señalado, para describir a los hombres individualmente dentro del grupo al que pertenecen. En relación con esto adquiere especial significado la noción de comportamiento desviado o conducta desviada. Desde una perspectiva sociológica se entiende por desviación aquello que, como el delito o el pecado, quiebra una norma o regla de un grupo ${ }^{2}$. De este modo, una conducta no puede existir como "desviada" independientemente de las normas y reglas que asignan el significado de desviación al acto. Este hecho tiene una enorme trascendencia de cara a determinar las tareas que debe abordar quien se plantea estudiar la desviación desde una perspectiva sociológica. Como ha señalado Freidson, por un lado, se trataría de prestar atención a las causas y tratamiento de la conducta desviada. Esta tarea se vería limitada a concentrarse en un determinado momento y lugar, puesto que, del mismo modo que son cambiantes los valores, las creencias y el conocimiento de una sociedad, también lo son los signos, conductas o atributos que sirven para establecer la clasificación de los mismos como crimen o pecado. Estas característica es la que pone de relieve la necesidad de plantearse una segunda tarea que permita contemplar la desviación desde una perspectiva que tenga más en cuenta esa idea de cambio: la de analizar la manera en que a unos determinados signos, conductas o atributos se les atribuye el significado de desviados. Adquiere así un marcado interés dentro de este enfoque el estudio del proceso social mediante el cual se crean las reglas que sirven para catalogar a unos individuos como desviados y para establecer el tipo de proceder que se debe seguir con ellos; unas

1 GidDEns, A. (1991), Sociología, Madrid, p. 65.

2 FREIDSON, E. (1978), La profesión médica, Barcelona, p. 220. 
reglas que, con frecuencia, no hacen sino sustituir a otras. Adoptando esta perspectiva se trataría de responder a cuestiones bien interesantes para un historiador cómo son las siguientes: ¿de qué modo una conducta llega a ser considerada desviada? ¿cómo llega a ser conceptuada como una clase de desviación y no otra? ¿qué efectos tiene la atribución de una clase particular de desviación en el tipo de relaciones entre quien así es clasificado y el resto de los miembros de la sociedad?? ${ }^{3}$.

El presente trabajo tiene como objetivo aportar algunas respuestas a esas preguntas. Para ello se plantea analizar la manera en que, en la Francia de la primera mitad del siglo XIX, se procedió a modificar la clase de desviación en la que había que situar un tipo de conductas que son, de forma casi general, especialmente preocupantes para la vida social: las delictivas. A partir de entonces, algunos individuos que transgredían determinadas leyes sancionadas por los códigos de justicia empezaron a ser situados dentro de esa otra categoría de desviación que es la enfermedad mental. Como veremos, tal proceso se encuentra estrechamente relacionado con la constitución en ese periodo de un nuevo profesional: el psiquiatra ${ }^{4}$. Es por esto por lo que se hace necesario, de cara a apreciar la forma en que este nuevo especialista médico planteó a la sociedad de su tiempo un cambio en la manera de catalogar determinadas conductas, examinar el lugar que reservaron a las mismas en sus clasificaciones de las enfermedades mentales.

Al objeto de evitar la dispersión, concentraré mi estudio en el análisis del lugar que en la nosología psiquiátrica francesa de la primera mitad del siglo XIX se reservó a una forma de desviación que resulta especialmente inquietante para casi todos los grupos humanos: el homicidio ${ }^{5}$. Aunque los alienistas incluyeron el comportamiento homicida como uno de los signos que era posible encontrar en individuos adscritos a la práctica totalidad de las entidades que catalogaron como especies de enfermedad mental, la nueva percepción que transmitieron de esa conducta vino aparejada sobre todo al desarrollo de una de ellas: la monomanía ${ }^{6}$. Es por esto por lo que, en las

3 FREIDSON (1978), pp. 218-220

4 Sobre el surgimiento y el desarrollo de la nueva profesión de alienistas en Francia puede verse el excelente libro de Goldstein, J. Console and Classify. The French Psychiatric Profession in the Nineteenth Century, Cambridge.

5 La enorme carga afectiva que el homicidio posee como forma de comportamiento desviado se muestra por ejemplo en el estudio de Weiss y Perry sobre las actitudes hacia el crimen y las conductas antisociales en varias culturas y subculturas. Un $84,9 \%$ de los encuestados consideraron como el peor crimen al "homicidio o a cualquier tipo de asesinato o intento de asesinato". WEISS, J.M.; PERRY, M.E. (1976), «Transcultural attitudes toward antisocial bnehaviour: the "worst" crimes», Social Science \& Medicine, 10, 541-545; p. 543.

6 El concepto de monomanía ha sido bien estudiado, dado que muy pronto se puso de relieve por los historiadores que se trataba de una de las más transcendentales aportaciones para el desarrollo temprano de las Psiquiatría de entre las realizadas por los alienistas franceses de la primera mitad del siglo XIX. Su utilidad para la renovación teórica y metodológica del estudio de las enfermedades mentales ya 
próximas páginas me ocuparé en primer lugar de exponer qué tipo de signos, conductas y atributos humanos fueron clasificados por los alienistas bajo ese rótulo y del lugar que dentro de la nueva categoría ocuparon las diversas formas de conducta homicida.

\section{UN NUEVO GÉNERO DE ENFERMEDAD}

El término monomanía fue introducido en el lenguaje médico a comienzos de la década de 1810 a 1820 por Jean-Etienne-Dominique Esquirol (1772-1840), con el objetivo de designar bajo esa denominación a la "locura parcial"7. Mostraba así un rasgo muy significativo de los incipientes especialistas franceses en el estudio de las enfermedades mentales: su interés por renovar la clasificación de las mismas ${ }^{8}$. La conveniencia de esta revisión había sido ya señalada por Philippe Pinel (1745-1826), el maestro de Esquirol, quién ya en 1801 llamó la atención sobre la necesidad de sustituir esas "distribuciones arbitrarias admitidas por los nosólogos para las vesanias"

\footnotetext{
fue puesta de relieve en 1946 por SAUSSURE, R. de (1846), «The Influence of the Concept of Monomania on French Medico-Legal Psychiatry (from 1825 to 1840)», Journal of the History of Medicine and Allied Sciences, 1, 365-397; pp. 395-396. Posteriormente, las consecuencias epistemológicas de la monomanía han sido bien examinadas por: FONTANA, A. (1973), «Les intermittences de la raison». En: Foucault, M. et al. (1973), Moi, Pierre Rivière, ayant égorgé ma mère, ma soeur et mon frère... Un cas de parricide au XIXe. siècle présenté par Michel Foucault, Paris, 333-350; pp. 341-349; y por GOLDSTEIN (1987), p. 152-196. Al desarrollo y puesta en práctica de la doctrina de la monomanía se ha atribuido también un papel relevante en la consolidación social de la psiquiatría como profesión. A este respecto pueden examinarse: ASTEL, R. (1973), «Les médecins et les juges». En FOUCAULT (1973), 315331; pp. 328-329; CASTEL, R. (1980), El orden psiquiátrico. La edad de oro del alienismo, Madrid, pp. 180-189; y GOLDSTEIN (1987), pp. 166-169 y 189.

7 Así lo recordaba él mismo en 1827 al señalar que hacía ya "más de quince años" desde que había "propuesto imponer a la locura parcial el nombre de monomanía". ESQUIROL, J.-E.-D., «Note sur la monomanie homicide». En: HOFFBAUER, J.-C. (1827), Médecine légale relative aux alienés et aux sourds-muets, ou les lois apliquées aux désordres de l'inteligence, 309-359, Paris; p. 311. La existencia de formas de locura con delirio parcial había sido constatada por la Medicina desde muy temprano. Pigeaud ha llamado la atención sobre la presencia de descripciones de estos cuadros en la obra de médicos de la antigüedad greco-latina. PIgEAUd, J. (1981), La maladie de l'âme. Etude sur la relation de l'âme et du corps dans la tradition médico-philosophique antique, Paris, pp. 131-132; PIGEAUD, J. (1987), Folie et cures de la folie chez. les médecins de la antiquité gréco-romaine. La manie, Paris, $\mathrm{p}$ 94. Por su parte, Berrios ha indicado los criterios por los que se distinguía la "locura parcial" de la "general" antes y durante el siglo XIX: 1.- Intensidad de los síntomas; 2.- Grado de implicación de la personalidad; 3.- Daño de funciones psicológicas selectivas; y 4.- Exclusividad de la ilusión. BERRIOS, G.E. (1985), «Obsessional disorders during the nineteenth century: terminological and classificatory issues». En: BYNUm, PORTER, R.; SHEPHERD, M. (1985), The Anatomy of Madness. Essays in the History of Psychiatry (Vol. I): People and Ideas, London, 166-187; p. 181 (nota, 60).

8 GoldSTEIN, J. (1987), p. 156.
} 
debido a que estaban "lejos de ser el resultado de una observación reiterada hecha sobre un gran número de alienados" 9 . Propuso por ello una nueva "división de la alineación mental" en cinco especies, en una de las cuales aparecía recogida la idea de la existencia de una "folie partielle". En efecto, entre los rasgos que Pinel señalaba como definitorios de la melancolía - la primera de las cinco especies de alineación mental que él establecía - figuraba el de consistir en un "delirio exclusivo sobre un objeto, o sobre una serie particular de objetos" existiendo, "por lo demás, libre ejercicio de todas las facultades del entendimiento $0^{10}$ ".

En 1816, al desarrollar la voz "folie" dentro del célebre Dictionnaire des sciences médicales publicado por Panckoucke, Esquirol mantuvo la división de las enfermedades mentales establecida por Pinel dentro de la segunda edición de su Traitél1: manía, melancolía, demencia e idiotismo. No obstante, consciente del valor que poseen la taxonomía y el vocabulario para fundamentar la autoridad científica, rechazó el término "melancolie" para las nosografías psiquiátricas. Consideraba que continuar utilizando en Medicina el término "melancolía" para referirse al delirio parcial resultaba inadecuado por dos razones: en primer lugar, en su acepción profana, dicho vocablo remitía a un concepto diferente al que los médicos aludían con esa expresión; en segundo, se hallaba relacionado con la noción fisiopatológica de la enfermedad procedente de la Antigüedad Clásica, que hacía de ella el resultado de un desequilibrio en la bilis negra. Propuso por ello el vocablo "monomanie" para designar la forma de enfermedad mental en la que "el delirio está limitado a un objeto o a un pequeño número de objetos ${ }^{12}$ ".

9 PINEL, P. (an IX, finales de 1800-comienzos de 1801), Traité médico-philosophique sur l'aliénation mentale, ou la manie, Paris, P. 135

10 Los otros rasgos del paciente melancólico serían los de presentar "algunas veces igualdad constante del humor, o inclusive estado habitual de satisfacción; en otros casos, hábito de abatimiento y de consternación, o bien acritud de carácter que puede ser llevada hasta el último grado de misantropía, [y] a veces hastío extremo de la vida". PINEL, P. (an IX), P. 149. Las otras cuatro especies morbosas de alienación mental que estableció Pinel fueron: 1.- Manía sin delirio; 2.- Manía con delirio o delirante; 3.- Demencia o abolición del pensamiento; y 4.- Idiotismo u obliteración de las facultades intelectuales y afectivas. PINEL, P. (an IX), "sectión IV", en especial pp. 155, 160, 165, 174.

11 Pinel, P. (1809), Traité médico-philosophique sur l'aliénation mentale (2. a ed.), Paris, pp. 138139. La nueva nosotaxia pineliana se mostraba así más próxima a otras dos clasificaciones tradicionales de la enfermedad mental: La de Doublet y Colombier y la de la Encyclopédie. Sobre esta última cuestión puede verse: GoldSTEIN (1987), pp. 45-46, 156; COLlÉE, M.; QuÉTEL, C. (1987), Histoire des maladies mentales, Paris, p. 70.

12 ESQUIROL (1816), «Folie», Dictionnaire des sciences médicales, par une société de médecins et de chirurgiens, 16, 151-240, Paris, p. 163. Sobre la oposición de Esquirol al uso del término "melancolía" por la incipiente psiquiatría pueden verse: PIGEAUD (1981), pp. 133-134; GoLDSTEIN (1987), p. 156; y JACKSON, S.W. (1989), Historia de la melancolía y la depresión desde los tiempos hipocráticos a la época moderna, Madrid, p. 145. 


\section{JOSÉ MARTÍNEZ PÉREZ}

La forma del delirio constituía, pues, el signo fundamental que permitía clasificar a un individuo como monomaníaco y distinguirlo, por ejemplo, del maníaco, en que "el delirio se extiende sobre todo tipo de objetos y se acompaña de excitación"13. Iba a ser precisamente el análisis de los rasgos que presentan los delirios de los pacientes monomaníacos lo que iba a permitir a Esquirol trazar de manera más ajustada el significado y los contenidos del nuevo término. Para empezar, Esquirol llamó la atención sobre la existencia de dos formas "opuestas" de monomanía. Una de ellas, la "lypemanía", estaría provocada por una pasión triste u opresiva y se caracterizaría por un delirio fijo, de índole similar a la pasión que lo provocaba, que daba lugar a deseos y determinaciones en consonancia con el mismo. La segunda forma, la "monomanía propiamente dicha", tendría como "signo característico" un "delirio parcial y una pasión excitante o alegre". Será esta última forma la que se convertirá prácticamente en sinónimo de "monomanía" y la que sufrirá nuevas revisiones que darán lugar a una mayor matización de los contenidos del término ${ }^{14}$.

La primera de ellas tuvo lugar en 1819. Esquirol llamó entonces la atención sobre la necesidad de modificar el status nosológico de las dos formas de primitiva monomanía. La monomanía debía de ser considerada como "una especie intermedia entre la lypemanía y la manía, ya que compartiría con "la lypemanía (melancolía) la fijeza y la concentración de ideas" y con la manía "la exaltación de las ideas y la actividad

13. Esquirol (1816), p. 163. Claramente expresaba este contraste cuando exponía el modo en que

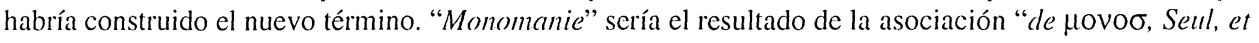
de $\mu \alpha v i \alpha$, délire sur un Seul objet, délire partiel". ESQuirol (1819a), "Monomanie", Dictionnaire des sciences médicales par une société de médecins et de chirurgiens, 34, 114-125, Paris, p. 114. Según Pigeaud, "es preciso (...) evitar traducir manía por el término demasiado general de locura. Es mejor, como lo ha hecho por otra parte la tradición médica, conservar el nombre de manía", dado que, desde aproximadamente el siglo II a.C., los médicos habían diferenciado entre la locura y la manía. Esta sería vista como una especie morbosa determinada, como una "enfermedad crónica, con alienación del espíritu sin fiebre". Parecería entonces que Esquirol estaría confundiendo un síntoma con toda la enfermedad, lo que es bastante improbable ya que, contrariamente a Pinel, conservaba básicamente, como ha destacado también Pigeaud, el concepto de manía procedente de la antigüedad clásica. PIGEAUD, J. (1987), pp. 7, 72-94, 221-222. La elección del término "delirio" para traducir $\mu \alpha v i \alpha$, en lugar de hacerlo por "manie", como hace en otras ocasiones de manera más acertada, creo que muestra el afán de Esquirol por destacar lo que para él constituye el rasgo principal de la enfermedad: la idea fija que se hace dueña de la mente del enfermo. Frente al delirio generalizado propio de la manía, la monomanía queda caracterizada por el delirio parcial.

14 Esquirol no pretendió haber sido el primero en distinguir entre csas dos formas de delirio parcial. Alude, por ejemplo, a la obra de Benjamin Rush Medical Inquiries and observations upon the diseases of the mind (Filadelfia, 1812), en la que este autor habría distinguido entre la "tristimanie" y la "aménomanie". Hay que señalar que, si bien el término monomanía obtuvo un gran éxito, el de "lypemanía", a pesar de que Esquirol esperaba que "el empleo" del mismo fuera capaz de consagrarlo, no gozó de la misma fortuna. Esquirol (1819b), "Mélancolie", Dictionnaire des sciences médicales par une société de médecins et de chirurgiens, 32, 147-183, pp. 150-151. 
física y moral"15. Las dos formas de la primitiva monomanía modificaban así su status nosológico: dejaban de ser variedades de una sola especie y se convertían ellas mismas en especies morbosas independientes y bien diferenciadas. La razón de que esta distinción no hubiera sido hecha antes radicaría, según Esquirol, en el hecho de que los autores preocupados por estudiar la locura "no habrían tenido en cuenta más que el delirio, sin ocuparse de otros síntomas": aquellos que tenían que ver con su "actividad física y moral", con su conducta ${ }^{16}$. La forma del delirio no bastaba ya, a pesar de seguir siendo el rasgo principal a tener en cuenta de cara a diagnosticar una monomanía, para determinar si un sujeto se encontraba bajo los efectos de la misma. El estudio de su comportamiento pasaba a ser un elemento fundamental de esa tarea.

Un nuevo modo de caracterizar a la locura se estaba elaborando, por tanto, en la Francia de las primeras décadas del siglo XIX. El concepto de monomanía estaba contribuyendo así, no sólo a difundir la idea de la existencia de formas de locura en las que el delirio puede estar restringido a un número limitado de objetos, sino, además, a divulgar la necesidad de prestar una enorme atención a los rasgos de la conducta de un sujeto de cara a establecer la presencia en él de una enfermedad mental. Así, pues, los signos para obtener el diagnóstico de la misma se ampliaban y con ello las posibilidades de incorporar dentro de la categoría de alienación mental a otras formas de desviación, como iba a ser el caso de ciertas conductas homicidas, que hasta entonces no se hallaban comprendidas en ella.

\section{UNA NUEVA VALORACIÓN DE DETERMINADOS COMPORTAMIENTOS}

En la primera edición de su Traité, Pinel, como indicamos más arriba ${ }^{17}$, hizo de la "manía sin delirio" una de las especies de las enfermedades mentales. Denominaba así aquellos cuadros en los que, bien de manera continua, bien en forma de accesos

15 ESQuirol (1819b), p. 115

16 Esos síntomas distintivos entre ambas enfermedades eran resumidos por Esquirol del siguiente modo: "La fisonomía de los monomaníacos es animada, expansiva, muy móvil; los ojos son vivos, a veces inyectados y brillantes. Su color es colorado e incluso muy rojo en la lypemanía (melancolía); los rasgos de la cara son inmoviles o crispados y concentrados; los ojos están fijos, la mirada es inquieta, el color es amarillo o pálido. Los lypemaníacos (los melancólicos) son víctimas de ideas tristes, dolorosas; son tímidos, desconfiados, suspicaces, buscan la soledad. Los monomaníacos, al contrario, son alegres, vivos, impetuosos, audaces, temerarios. Los primeros se niegan a cualquier ejercicio, hablan poco; todas sus funciones se hacen penosamente y con lentitud. Los segundos son de una gran movilidad; hacen mucho ejercicio; son ruidosos, parlanchines; nada parece poner obstáculo al cjercicio de sus funciones. La marcha de la monomanía es más enérgica, más aguda; su duración es más corta; su terminación es favorable más a menudo. Todo lo contrario sucede en la lypemanía" ESQUirOL (1819a), pp. 115-116.

17 Véase la nota 10. 
periódicos, no se podía observar ninguna alteración "en las funciones del entendimiento, la percepción, el juicio, la imaginación, la memoria, etc.", pero sí era posible apreciar alguna "perversión en las funciones afectivas, impulso ciego a los actos de violencia, e incluso un furor sanguinario"18. De este modo, por un lado, y como él mismo señalaba, Pinel se oponía a la opinión de John Locke, mayoritaria en ese momento, que defendía la imposibilidad de que pudiera haber manía sin que existiera un trastorno intelectual. Por otro, al defender la presencia de formas de alineación mental caracterizadas por el hecho de que los pacientes no presentarían "lesión de entendimiento", sino que estarían "dominados por un tipo de instinto de furor, como si solo las facultades afectivas hubieran sido lesionadas"19, el médico francés impulsaba la difusión de la idea de que pudieran existir formas de locura que se manifestaran sin alteración de la facultad intelectual. Hay que llamar la atención sobre la forma de entender la psique humana que lleva aparejada la anterior descripción de un tipo de enfermedad mental por el profundo significado que tendrá de cara a la incorporación de ciertas conductas homicidas como formas de alienación. Contrariamente al asociacionismo de Locke o al de Condillac, quien fue su guía en otros aspectos de su obra, Pinel plantea la independencia de las facultades mentales y, con ello, la posibilidad de que pueden existir lesiones aisladas del entendimiento, los afectos o la voluntad 20 .

Esta forma de entender la psicología humana iba a estar también presente en la obra de su discípulo Esquirol. No obstante, éste iba a desconfiar en un primer momento de la posibilidad de que pudieran existir lesiones aisladas de cada una de las funciones, de que fuera posible la presencia de formas de manía en las que el delirio estuviera ausente. Prefirió incluir al principio ese tipo de casos dentro de las monomanías $^{21}$. Indicaba que en estas formas de enajenación mental no habría "evidentemente más que un delirio parcial". Para él, este tipo de pacientes

\footnotetext{
18 PINEL (año IX), p. 155. No obstante, en la segunda edición de la obra, la "manie sans délire" iba a quedar transformada por el autor en una simple variedad de la manía. Las razones de ello eran aportadas por el propio Pinel señalando que los afectados por esta alteración proporcionarían, "en el momento en el que razonan con rectitud", otros signos de "extravío en sus acciones" y ofrecerían también "otros caracteres propios de los maníacos". Pinel (1809), p. 138.

19) PINEL (1809), pp. 155-156.

20) La puesta en marcha del tercero de los criterios -el que tenía en cuenta el daño de funciones psicológicas selectivas - que, como hemos expuesto (véase nota 7), habrían permitido la distinción entre "locura parcial" y "locura general", sólamente habría sido posible a partir de comienzos del siglo XIX. Como ha indicado Berrios, ello se debió a la reintroducción en ese periodo, por el influjo ejercido por Kant y los filósofos escoceses, de las facultades psicológicas: la visión de que la psicología humana podía ser analizada operativamente en facultades autónomas. Este recurso a las facultades psicológicas habría sido, según Berrios, "más claro” en Esquirol que en Pinel. BERRIos (1985), p. 181 (nota 60).

21 Según esponía en 1819, "las pasiones bajo cuyo imperio viven los monomaníacos no son siempre agradables y alegres; las acciones de estos enfermos no son siempre inocentes o determinadas por senti-
} 


\begin{abstract}
"creen obedecer a la voz del cielo que les ordena los más penosos sacrificios. Confundidos por las alucinaciones, ceden a una voz interior que les grita mata, mata, o bien, sin que puedan darse cuenta de los motivos que lo determinan, son arrastrados a actos de furor cuyos horribles efectos deploran después de que ha pasado el paroxismo"22
\end{abstract}

Admitiendo, por tanto, la existencia de cuadros en los que la facultad del entendimiento de la psique humana parecía estar conservada, llamaba la atención sobre el hecho de que ello no implicaba una ausencia de delirio. Lo que ocurriría es que éste afectaría únicamente a la voluntad, siendo su existencia detectable básicamente por la conducta que mostrara un individuo ${ }^{23}$. Se trataba, por tanto, de una forma de enajenación cuyos signos más manifiestamente visibles serían comportamientos de los pacientes del tipo de la entrega "a los más grandes excesos" o de acciones "de la ferocidad más atroz". Era preciso, en consecuencia, modificar tanto el término "manía sin delirio", como su posición dentro del cuadro nosológico de las especies de alineación mental; y para Esquirol lo más adecuado iba a ser considerarla, como hemos visto, una forma de monomanía.

Esta posición, la de que no existía ninguna forma de locura en la que el delirio se hallara ausente, iba a ser admitida y sostenida también en ese momento por los alumnos de Esquirol. Jean-Pierre Falret (1794-1870)24 y Etienne-Jean Georget (1795$1828)^{25}$ son buenos ejemplos de ello. Este último, no obstante, iba a modificar más

mientos reales y fundados. Turbados por alucinaciones, arrastrados por pasiones violentas e incluso feroces, hay algunos que se entregan a los más grandes excesos, que cometen actos de la ferocidad más atroz, empujados por un furor reflexivo e incluso razonado. Es a esta especie a la que deben ser referidas las diversas observaciones publicadas bajo el título de manía sin delirio”. Esquirol (1819a), p. 123.

22 Ibidem.

2.3 Sobre el manejo del concepto de voluntad por Esquirol puede verse: BERRIOS, G.; GILI, M. (1995), «Will and its disorders: a conceptual history», History of Psychiatry, 6, 87-104, pp. 95-96.

24 En su tesis doctoral, Falret dedicaba numerosas páginas a analizar la cuestión de si la manía podía existir sin una alteración del entendimiento. En sus conclusiones señalaba lo siguiente: "que en la manía denominada sin delirio hay no solo perversión en las facultades afectivas, sino también lesión en las funciones del entendimiento; que los enfermos afectados por ella no están dominados en absoluto por un impulso ciego a los actos de violencia; que, cuando recobran la razón y pueden dar cuenta de sus acciones, de sus movimientos, lo cual sucede habitualmente, reconocen que no han sido en absoluto automáticos, sino que han sido el efecto de una lesión de la percepción, del juicio, de la imaginación, etc". Falret señalaba, además, que los casos de "manie sans délire" podían ser clasificados como formas de manía, pero que, "más a menudo", corresponderían a cuadros de monomanía. FALRET, J.-P. (1819), Observations et propositions médico-chirurgicales. Thèse presentée et soutennue à la Faculté de Medecine de Paris, le 30 décembre 1819, Paris p. 15.

25 Georget señaló en 1820 que la manía sin delirio debía "formar una variedad de la monomanía", una especie de locura caracterizada por "un pequeño número de ideas fijas, dominantes, exclusivas, sobre las cuales da vueltas el delirio, y un razonamiento a menudo bastante sano sobre cualquier otro objeto". Este autor, que admitiría, al igual que su maestro, dos formas de monomanía - la lypemanía o la 
adelante su posición.En 1820, Georget había insistido sobre el hecho de que uno de los rasgos más característicos de la monomanía consistía en una alteración del comportamiento caracterizada muchas veces por "una inclinación a la ferocidad, por un deseo, una necesidad sin motivos de destruir seres vivos e incluso seres humanos"26. Cinco años más tarde, este signo representativo de la monomanía iba a permitirle, por una parte, precisar los contenidos y denominación de esta "variedad" de locura, y, por otra, dotar a ese concepto, y a través de él a la nueva medicina mental, de una gran difusión social. En relación con esto conviene tener presente el doble sentido que Blaxter ha encontrado en el modo de considerar esa actividad esencial de la clínica y del proceso de catalogación de la enfermedad humana que es el diagnóstico. Esta autora ha llamado la atención sobre la existencia de una cierta confusión entre dos significados de este término: diagnóstico como categoría, como una lista de enfermedades; y diagnóstico como proceso, esto es, las cosas que el médico hace para establecer esa lista. Como esta autora señala, ambos significados no son separables sino que son interdependientes. El diagnóstico-como-proceso es dependiente del diagnóstico-como-categoría ya que el acto de describir una enfermedad está influido por las descripciones aceptables o disponibles en el universo relevante del conocimiento médico; y a la inversa, la naturaleza de los diferentes conjuntos de categorías inventadas dependerá del propósito de categorización, por lo que, en cierto sentido, las clasificaciones son el resultado del proceso ${ }^{27}$. Creo que tener en cuenta esa doble significación del diagnóstico es muy útil para apreciar como se incorporaron determinadas formas de conductas criminales al catálogo de las enfermedades mentales.

En efecto, la introducción de las mismas como formas de enajenación mental estuvo relacionada de forma clara con el objetivo que Georget perseguía con su obra: ilustrar diversas cuestiones médico-legales relacionadas con una "enfermedad", como era la alienación mental, que consideraba "todavía poco conocida en alguna de sus variedades" por aquéllos — magistrados, abogados, miembros del jurado y médicosque debían declarar como expertos-que eran "llamados a juzgar a sus semejantes" en los tribunales y en cuyas manos se encontraba, por tanto, "la vida, el honor, la

\footnotetext{
melancolía, caracterizada por un delirio triste; y la monomanía en la que el delirio sería predominantemente alegre-, tenía además mucho cuidado en dejar bien claro que "en muchos casos, el delirio no está en absoluto limitado a la idea principal; sólamente es menos general, más oculto, más difícil de reconocer que en la manía". GEORGET, E.-J. (1820), De la folie. Considérations sur cette maladie: son siége et ses symptômes; la nature et le mode d'action de ses causes; se marche et ses terminaisons; les différences qui la distinguent du délire aigu; les moyens de traitment qui lui conviennent; suivies de recherches cadavériques, Paris, pp. 108-109.

26 Georget (1820), p. 110.

27 BLAXTER, M. (1978), «Diagnosis as category and process: the case of alcoholism», Social Science \& Medicine, 12, 9-17.
} 
fortuna y la libertad" de un individuo ${ }^{28}$. Para cumplir ese objetivo, en el que, como veremos, se hallaba también presente un interés por reforzar la posición social de los alienistas, Georget iba a proceder a recuperar una categoría diagnóstica pineliana: la manía sin delirio. Señalando, como había hecho Esquirol, que entre los trastornos de la alienación mental era posible distinguir entre "lesiones de la voluntad" y las llamadas "lesiones de la inteligencia o delirio"29, se iba a alejar no obstante, como anunciamos más arriba, de su maestro a la hora de considerar el modo de presentación de los síntomas dependientes de una y otra:

\footnotetext{
"Comúnmente estos dos elementos de la alienación mental se encuentran reunidos en el mismo enfermo (...) Pero a menudo uno u otro de estos dos órdenes de fenómenos predomina; a veces incluso uno de ellos existe sólo o aproximadamente sólo. Es especialmente importante conocer las lesiones exclusivas de los sentimientos y las pasiones, pues, para el vulgo, y en consecuencia para los magistrados, no hay locura más que cuando las ideas están perturbadas, los juicios (son) falsos y los razonamientos erróneos":31)
}

Georget, por tanto, recuperaba la vieja idea de Pinel de que la locura no era incompatible con la presencia de un juicio y una inteligencia bien conservadas. Es más, la iba a hacer desempeñar un papel fundamental en la revisión del concepto de monomanía que llevaba a cabo en su trabajo. En efecto, consideraba que diversas observaciones permitirían establecer que el hombre podría verse sometido a la acción de una enfermedad mental que haría "nacer en él horribles inclinaciones" y que le llevaría a los "excesos más condenables" aun cuando la razón no se encontrara "en absoluto alterada"31. Este hecho se pondría sobre todo de relieve, aunque no de manera exclusiva, en un tipo de cuadros que habrían sido ya descritos por autores anteriores y que él iba a clasificar bajo el rótulo de monomanía homicida ${ }^{32}$. Georget, no obstan-

28 GEORGET, E.-J. (1825), Examen médical des procés criminels des nommés Léger, Feldtmann, Lecouffe, Jean-Pierre et Papavoine, dans lesquels l'aliénation mentale a été alléguée comme moyen de défense. Suivi de quelques considérations médico-légales sur la liberté morale, Paris, p. 1. Hay que tener presente que el artículo 64 del Código Penal napoleónico, vigente en ese momento en Francia, establecía que "Il n'y a crime ni délit lorsque le prévenu était en démence au temps de l'action". Cit. en: GEORGET (1825), p. 98. La enajenación mental podía privar también a quien la padecía del libre ejercicio de sus derechos civiles e, incluso, de su libertad. GEORGET (1825), p. 102.

29) GEORGET (1825), p. 69.

31) GEORGET (1825), pp. 69-70

31 GEORGET (1825), p. 95.

32 Georget llevaba a cabo en su trabajo una revisión de los autores - Pinel, Fodéré y Esquirol, entre otros- que habrían descrito cuadros de monomanía homicida aun sin nombrarla de ese modo. Hay que señalar también que este autor llamaba asimismo la atención sobre la existencia de otras formas de monomanía, como la caracterizada por la "inclinación al robo", cuyo rasgo común sería el de aparecer en ellas una tendencia irresistible a cometer actos delictivos. GEORGET (1825), pp. 72-95. 
te, consideraba necesario hacer notar que el rasgo más sobresaliente y característico de esta forma de alienación mental, la inclinación que presentarían los enfermos a matar personas, estaría acompañada "le plus souvent de l'aberration dans les idées". Distinguía así entre dos formas de monomanía homicida: una "sin delirio"; y otra, que representaría la "mayor parte" de los casos, en la que "la inclinación al homicidio" no sería "más que el resultado del trastorno de las ideas"33.

Pero este significado que Georget asignaba a ciertas conductas no era precisamente compartido por el resto de la sociedad. Hay que señalar que ya la "manie sans délire", a pesar de las reservas con la que fue contemplada en un primer momento por la incipiente psiquiatría, era un concepto que estaba siendo manejado con frecuencia ante los tribunales ${ }^{34}$. No obstante, si atendemos a alguno de los procesos analizados por Georget en su trabajo, da la impresión de que el recurso a esta forma de locura para excusar las acciones criminales no parece que estuviera siendo tenido demasiado en cuenta por los jueces y jurados, al considerarlo un "error funesto"35. Esta situación no solo suponía poner en cuestión la nosología de las enfermedades mentales, sino la labor de los alienistas y la objetividad de su aportaciones ${ }^{36}$. Por ello, la monomanía homicida, sobre todo en su forma no delirante, se convertía en una categoría diagnóstica clave para el devenir de la Psiquiatría. Al tratarse de una forma de locura que resultaba difícil de detectar para los no entrenados en el estudio de la misma, representaba un buen argumento en manos de los alienistas para legiti-

33 Georget (1825), p. 95.

34 GOLDSTEIN (1987), p. 173.

35 Georget señalaba que numerosos abogados estaban intentando librar a sus defendidos en las causas "desesperadas" haciendo pasar "las pasiones violentas" por "verdaderas monomanías". GEORGET (1825), p. 117. No obstante, como indicaba este mismo autor, la "manía sin delirio" no había sido "más que raramente tomada en consideración ante los tribunales, e incluso [era] aún generalmente rechazada por los magistrados como un error funesto". GEORGET, E.-J. (1828), Nouvelle discussion médico légale sur la folie ou aliénation mentale, suivie de l'examen de plusieurs procès criminels dans lesquels cette maladie a été alléguée comme moyen de défense, Paris, pp. 46-47. Pinel ya había dado muestras de ser consciente de las dificultades que iba a encontrar esta variedad de locura para ser aceptada por los profanos y, concretamente, por los juristas: PINEL (1809), p. 190-191.

36 No puede sorprender por ello que Georget quisiera defender la autoridad de los expertos frente a las opiniones de los profanos, y que la reivindicara de este modo: "En el mayor número de casos, la alienación mental es fácilmente reconocida por todo el mundo. Pero hay casos dudosos, donde las personas, incluso las más instruidas, no se pueden pronunciar con certidumbre (...) [Es preciso, por tanto], que los magistrados se convenzan de la necesidad de ilustrarse constantemente con las luces de numerosos hombres del arte cuando es preciso pronunciarse sobre el estado de los acusados. Además de que los profanos no tienen los conocimientos necesarios para pronunciarse en los casos oscuros, la decisón de los médicos tendrá siempre mucho más peso sobre la opinión pública. Es muy importante que el pueblo, que comprenderá dificilmente que se pueda tener accesos de manía furiosa y homicida sin alteración del juicio, se apoye con confianza en la opinión de los médicos y no crea que se le ha querido sustraer un culpable de la vindicta pública". GEORGET (1825), p. 72. 
marse socialmente, para mostrar la necesidad y la conveniencia de que sus opiniones sobre las enfermedades mentales fueran asumidas por aquellos que, como era el caso de los jueces y miembros del tribunal, no eran expertos en su estudio ${ }^{37}$.

Esquirol fue pronto consciente de ello. Una buena muestra a este respecto es, como veremos a continuación, su cambio de posición frente a las formas de locura sin delirio.

\section{NIHIL A CRIMINE, NULLA FICTA, A MORBO TOTA.}

Con esa frase - "nada por crimen, nada fingido, todo por enfermedad" - Esquirol quería "caracterizar" el asesinato cometido por los monomaníacos homicidas ${ }^{38}$. Parafraseaba así a quienes, encargados de examinar a finales del siglo XV a una acusada de brujería, concluyeron su informe sobre la misma con una frase que según expresaba el gran alienista francés habría servido de regla a partir de entonces a los jueces que tuvieron que pronunciarse sobre la suerte de las brujas y los magos": nihil a demone; multa ficta, à morbo pauca —nada por demonios, mucho por fingimiento, pocas cosas por la enfermedad-. De este modo Esquirol mostraba buena parte de los objetivos que los psiquiatras querían cubrir con esa categoría diagnóstica. De un lado, librar a unos pobres enfermos de un destino tan injusto como lo había sido en etapas más oscuras de la historia el de las acusadas de brujería, lo que les permitía presentar a la monomanía homicida rodeada de una aura humanitaria. De otro, el de conseguir para sí el reconocimiento por parte de la sociedad de su condición de expertos en el fenómeno de la locura, lo que pasaba por hacer valer sus diagnósticos de forma sistemática en las salas de justicia.

Pero la empresa de lograr que los tribunales aceptaran el significado de enfermedad mental que los alienistas, tras sus peritajes forenses, establecían para ciertos comportamientos no estaba resultando, como señalamos antes, nada fácili ${ }^{39}$. Aunque el concepto de monomanía homicida estaba ejerciendo ya una cierta influencia en las decisiones de los tribunales ${ }^{40}$, el líder de los alienistas franceses no podía permane-

\footnotetext{
37 Sobre el valor, especialmente puesto en relación con el concepto de monomanía, de la práctica médico-legal para el desarrollo de la psiquiatría pueden examinarse: SAUSSURE (1846), pp. 375-396; CASTEl (1973), pp. 180-189; GoldSTEIN (1987), pp. 166-169, 184-189.

38 ESQuirol (1827), p. 359.

39 El propio Georget reunía y discutía en un folleto las principales opiniones vertidas en contra de esos diagnósticos. GEORGET, E.-J. (1826), Discussion médico-légale sur la folie ou aliénation mentale, suivie de l'examen du procés criminel d'Henriette Cornier, et de Plusieurs autres procès dans lesquels cette maladie a été alleguée comme moyen de défense, Paris, pp. 1-69.

40) De hecho, Charles-Chrétien-Henry Marc(1771-1840) utilizó por primera vez en 1826 este concepto en la defensa de una acusada que no fue absuelta pero no fue condenada a la pena capital. Su 
cer ajeno a un estado de cosas poco favorable a los intereses de la disciplina que cultivaba ${ }^{41}$. Su apoyo más explícito a la doctrina de la monomanía homicida iba a llegar en 1827 en forma de una extensa nota aparecida en un volumen dedicado a los problemas forenses relativos a las enfermedades mentales. En su trabajo, Esquirol iba a intentar no solo difundir un nuevo modo de entender determinadas conductas delictivas, sino tambien proporcionar un cuadro acabado de los signos y síntomas por el que las mismas podían ser catalogadas como una forma de alienación mental: la monomanía homicida.

En primer lugar, mostraba su interés por combatir el estereotipo cultural vigente acerca de la locura. Hablar de un loco, decía al comienzo de su trabajo, "es para el vulgo hablar de un enfermo en el que las facultades intelectuales y morales están todas desnaturalizadas, pervertidas o abolidas"42. Mostrando su interes por modificar esa percepción de la patología mental indicaba que en la manía, pero de forma "más notable" en la locura parcial, en la monomanía, las cosas se presentaban de otro modo. Recurriendo a la idea de la división de la mente en tres distintas facultades - intelectuales, afectivas y volitivas- que podrían lesionarse aisladamente, llamaba la atención del lector sobre el hecho de que

"la locura parcial no tiene siempre por carácter la alteración de la inteligencia. A veces, la facultades afectivas son las únicas lesionadas. A veces, no se observa desorden más que en las acciones" 4.3

Esta introducción le servía de base para comenzar su exposición de una de las "especies" de monomanía que, como el resto de ellas, tomaría su nombre "del objeto del delirio". La monomanía homicida sería así "un delirio parcial caracterizado por un impulso más o menos violento al homicidio"44.

\footnotetext{
informe forense fue publicado ese mismo año. MARC, C.-C.-H. (1826), Consultation médico-légale pour Henriette Cornier, fenme Breton, accusée d'homicide commis volontariement et avec prémeditation précedée de l'acte de l'accusation, Paris.

41 Michel Gourevitch ha señalado que, en lo que tiene que ver con la nosografía, Esquirol es "lacónico y abstracto", mientras que el clínico es "fenomenólogo y describe sin clasificar nunca". Este autor señala que hay una excepción a esta afirmación: la monomanía homicida. A esta especie, lo que habla de su interés por ella y de la importancia que la concedía, Esquirol no sólo dedicó su única monografía dedicada a una monomanía, sino que se ocupó de ella con continuidad. GourEviTCH, M. (1983), «Esquirol et la nosographie». En: POSTEL, J.; QUÉTEL, C. (1983), Nouvelle histoire de la Psychiatrie, 157-163; pp. 160-161.

42 ESQUIROL (1827), p. 309.

43 ESQuirol (1827), p. 310.

44 ESQUIROL (1827), p. 311.
} 
Aunque esta manera de presentar esta especie morbosa pudiera inducirnos a pensar en el hecho de que Esquirol exigía la presencia de una alteración de la inteligencia para atribuir a los homicidas el significado de enfermos mentales, muy pronto mostraba que su modo de pensar al respecto era diferente. Ello pasaba por conceder al delirio un nuevo significado. En efecto, de inmediato llamaba la atención sobre la existencia de "dos formas bien distintas" de esta monomanía. En algunos casos,

"el homicidio es provocado por una convicción íntima, pero delirante; por la exaltación de la imaginación ofuscada; por un razonamiento falso, o por las pasiones en delirio. Siempre el monomaníaco es movido por un motivo confesado y fuera de razón, y siempre ofrece signos suficientes del delirio parcial de la inteligencia o los afectos" 4.5

Pero en otras situaciones, el monomaníaco homicida no presentaría

\begin{abstract}
"ninguna alteración apreciable de la inteligencia o de los efectos. Es arrastrado por un instinto ciego, por una idea: por alguna cosa indefinible que le empuja a matar; c incluso cuando su conciencia le advierte del horror del acto que va a cometer, la voluntad lesionada es vencida por la violencia del arrastre; el hombre está privado de la libertad moral, cs presa de un delirio parcial, es monomaníaco, es loco"46
\end{abstract}

El delirio adquiría así un nuevo alcance. Ya no se trataba de un síntoma de alteración en las funciones intelectual o afectiva. Un "instinto ciego", una "idea" o "algo indefinible" que arrastraran a los individuos a cometer un homicidio debían ser tambien considerados como delirios y, como consecuencia de ello, las personas que presentaran una conducta homicida bajo ese estado debían ser catalogadas como locos, como irresponsables. Ello pasaba por enfrentarse al punto de vista sostenido por la sociedad de la época al respecto, según el cual, como el propio Esquirol señalaba, sólo "por el extravío de la razón" se perdería el libre albedrío. Para Esquirol, del mismo modo que la inteligencia y la sensibilidad moral pueden ser pervertidas o abolidas, también "ese complemento del ser intelectual y moral" que sería la voluntad podría ser "turbado o aniquilado"47.

¿¿Es que la voluntad [—-se preguntaba Esquirol abundando en este sentido-], como el entendimiento y los afectos, no se extravía por vicisitudes, siguiendo mil circunstancias de la vida? ¿Es que el niño y el viejo tienen la misma fuerza de voluntad que el adulto? ¿Es que

45 ESQUIROL (1827), p. 311.

46 ESQuirol (1827), pp. 311-312.

47 ESQUiROL (1827), p. 319. 


\begin{abstract}
las pasiones no reblandecen o no exaltan la voluntad? ¿Es que la educación y mil otras influencias no modifican el ejercicio de la voluntad? Si es así, ¿por qué la voluntad no sería sometida a trastornos, a perturbaciones, a debilidades enfermizas por muy incomprensible que esto sea para nosotros?"48
\end{abstract}

La lectura de este párrafo muestra no sólo hasta qué punto la incorporación a la psiquiatría francesa de la teoría de la división de la mente humana en tres facultades distintas desempeñó un papel relevante en la configuración de la doctrina de la monomanía, sino también que en la delimitación de esta entidad morbosa ejerció un influjo fundamental su aplicación en la práctica forense. Expresión de ello es también el modo en que Esquirol procedía a caracterizar el cuadro. En efecto, tras exponer diversos casos de monomanía homicida, sistematizaba en primer lugar los síntomas y signos más característicos de esta forma de locura. La semiología del cuadro aparecería presidida por una constancia en "casi todos los individuos" estudiados de "una constitución nerviosa, de una gran susceptibilidad" y de "alguna cosa singular en el carácter, de rareza en el espíritu". Antes de la aparición del deseo de matar serían "dulces, buenos, honestos". En todos los casos en los que el acto homicida no se ejecutara "inmediatamente tras el impulso", sería posible encontrar en la biografía del sujeto un cambio marcado en su "sensibilidad física y moral", en su "carácter" o en su "manera de vivir". Este cambio sería siempre fácil de precisar. Sería posible encontrar las causas físicas o morales que habrían determinado la enfermedad. El impulso homicida se vería acompañado o precedido de cefalalgia, males de estómago o dolores abdominales. La visión de instrumentos con los que cometer el homicidio aumentaría el impulso. En casi todos los casos habría también tentativas de suicidio. No existiría ningún motivo para desear la muerte de las victimas, sino que las escogerían entre sus seres más queridos ${ }^{49}$.

Pero el cuadro semiológico de la monomanía homicida no se completaba con estos signos y síntomas. Junto a ellos y ocupando un lugar muy significativo, Esquirol iba a presentar los procedentes de la práctica médico-forense. Para establecer el diagnóstico diferencial entre esa enfermedad y el homicidio criminal era preciso recurrir a datos que tenían que ver con las circunstancias en las que el acto desviado se había producido: el monomaníaco actuaría aislado, sin complices; su comportamiento no respondería a un comportamiento criminal; no cometería su acción contra personas que pudieran representar un obstáculo o una amenaza para sus intereses, sino que atentaría contra personas que le son indiferentes o queridas; cuando cum-

48 ESQUIROL (1827), pp. 319-320.

49 ESQuirol (1827), p. 351. 
pliera su deseo no tendría nada en el pensamiento, "ha matado, todo ha terminado para él, el fin se ha alcanzado"50.

De este modo, una nueva especie morbosa quedaba caracterizada. Con ello, un significado inédito era atribuido por parte de la psiquiatría a ciertas conductas homicidas que hasta entonces eran contempladas como formas de esa categoría de comportamiento desviado que es el delito. Aunque ya con anterioridad la conducta de ciertos individuos que atentaban contra la vida de sus semejantes era incluida dentro de esa otra forma de desviación que es la enfermedad mental, se hacía obligado para ello la presencia en esas personas de un desorden manifiesto de la inteligencia, cuyo síntoma más relevante era el delirio. Los alienistas hacían ahora aparecer también dentro de la categoría de enfermedad mental, a conductas homicidas en las que no era posible apreciar una lesión del entendimiento, en las que no era evidente al presencia de un delirio, sino que sólo se caracterizaban por una alteración de la voluntad, por esa "inclinación irresistible" que conducía a determinadas personas a cometer un asesinato. Como cabía esperar, la sociedad francesa del momento no iba a compartir de inmediato ese significado que los incipientes psiquiatras otorgaban a ciertas formas de comportamiento homicida. Así lo expresaba años más tarde Louis Delasiauve (1804-1893):

\footnotetext{
"Una sensación inmensa se produjo en la magistratura y en el mundo por la designación [-se refiere a la de monomanía para determinados comportamientos-] de Esquirol. Una interpretación (...) literal hizo creer en la revelación de una variedad mórbida: las pasiones transformadas en locuras; los crimenes tanto más excusados cuanto más monstruosos; la moral perdiendo su base, la ley su sanción, la sociedad sus garantías; y, siguiendo la enérgica expresión de M. Dupin [—un magistrado-]: 'Charenton reemplazando a la Bastilla'. Tales fueron las previsiones siniestras que esta doctrina inspiró y que la indiscreción de ciertos alegatos contribuyó a afirmar"51
}

Los alienistas habían abierto, por tanto, un duro proceso de negociación con diversos sectores de la sociedad al objeto de conseguir que su modo de interpretar determinadas conductas adquiriera una aceptación general. En ese debate no sólo estaba en juego el destino que determinados individuos iban a tener - la guillotina, la cárcel o el manicomio-, sino también el grado de reconocimiento social que los saberes y prácticas psiquiátricos y con ello el status de quienes los detentaban, habían de poseer. Es por esto por lo que en el diagnóstico-como-categoría de monomanía homicida iba, como veremos a continuación, a influir de una forma considerable el

50) ESQUiROL (1827), p. 353-354.

51 Delasiauve (1853), «De la monomanie au point de vue psychologique et légal», Annales médico-psychologiques, 5, 353-371, p. 354 
diagnóstico-como-proceso, el hecho de tratarse en la mayor parte de los casos de diagnósticos realizados con un fin médico-legal y teñidos siempre de una sensación de que había algo más en la palestra que la suerte de un individuo, de que se estaba juzgando también a las aportaciones de una nueva disciplina médica y a quienes las estaban efectuando.

\section{ASCENSO Y CAÍDA DE UNA ENTIDAD NOSOLÓGICA}

En 1833 Marc iba a realizar algunas "consideraciones" acerca de la monomanía que resultan muy útiles para mostrar los problemas que la doctrina estaba encontrando en la sociedad francesa. El autor se preguntaba sobre el origen del "descrédito" por el que "todavía" estaría marcada "la doctrina médico-legal de la monomanía" y, para él, la respuesta se hallaría en una "reunión de circunstancias"52. La primera de ellas tendría que ver con la existencia de un conflicto de carácter profesional. En opinión de Marc, el afán de los jurisconsultos franceses por ejercer una supremacía sobre los médicos les estaría llevando, por un lado, a cuestionar la existencia de la monomanía, con la negativa influencia que de ello se derivaba de cara a que los jurados aceptaran este diagnóstico pericial, y por otro a cuestionar el papel de los médicos como expertos testigos en los casos en los que se planteaba la posible enajenación mental del autor de un homicidio ${ }^{53}$.

La segunda circunstancia que habría impedido la aceptación general por la sociedad francesa de la monomanía de hallaría relacionada con el hecho de que reinara

"en Francia entre muchas personas (...) un espíritu religioso mal entendido, que [habría] militado contra la realidad de la monomanía y de las propensiones irresistibles que ordinariamente la acompañarían" $5+$

52 MARC (1833), «Considérations médico-légales sur la monomanic et particulièrement sur la monomanie incendiaire», Annales d'hygiène publique et de médecine légale, 10, 357-474, p. 362.

53 MARC (1833), pp. 362-3. Entre los juristas que más se esforzaron en debatir con los médicos figuraba un joven abogado parisino - Élias Regnault-, quien publicó tres folletos poniendo en duda la existencia de la monomanía y la pretensión de los médicos de arrogarse en exclusiva la capacidad de establecer la existencia de enajenación mental en una persona: (1828), Du degré de compétence des médecins dans les questions judiciares relatives aux aliénations mentales, et des théories physiologiques sur la monomanie, Paris; (1830a), Nouvelles réflexions sur la monomanie homicide, le suicide, et la liberté morale, Paris; (1830b), Jurisprudence Médico-Légale. Examen critique d'un rapport de MM. Esquirol et Ferrus sur deux homicides commis par un homme atteint de monomanie avec hallucinations, Paris.

54 MARC (1833), p. 366. 
Quienes mantenían estas críticas sostendrían que el hecho de admitir esas "propensiones" equivaldría a "negar la existencia del alma". Para ellos, la "admisión de la monomanía como excusa en materia de crimen" conduciría "necesariamente al materialismo ya que" haría "derivar de la organización física los actos más inmorales"55. Este tipo de opiniones constituían sin duda, más allá de un conflicto entre diferentes posiciones en materia religiosa, un reflejo del debate entre dos modos de entender las funciones mentales que se hallaban enfrentados en la Francia del momento: el sostenido por los llamados "fisiologistas"; y el mantenido por los "psicologistas"56.

Por último, Marc planteaba como tercer origen de la falta de asentimiento de sus compatriotas ante la nueva entidad morbosa la actitud de los médicos. Éstos, al aplicar "demasiado abundantemente" ese diagnóstico, habrían "contribuido a retardar su propagación" ya que "ver monomaníacos por todas partes es llegar a que no se les vea en ninguna"57. Así pues, el último factor que estaba operando para limitar la extensión entre los franceses de un nuevo modo de contemplar determinadas conductas desviadas se hallaba relacionado con el propio desarrollo del conocimiento y de la práctica médica. La aparición de una nueva entidad nosológica permitía a los médicos disponer de una categoría en la que encuadrar a determinados sujetos y parece que, en efecto, el elevado número de individuos que eran adscritos a la misma resultaba excesivo a una sociedad que sólo desde unos pocos años antes había oido hablar de la misma y que acusaba a los médicos de ver monomaníacos "por todas partes". Ahora bien, creo que, en relación con el papel de los propios medicos en el destino que la monomanía estaba teniendo, Marc no hacía alusión a un problema que también ejercía una cierta influencia: el de que no todos ellos aceptaban la existencia de una especie de enfermedad mental de las características de la monomanía homicida instintiva ${ }^{58}$. Achille Foville (1799-1878), a quien Esquirol había hecho nombrar en

55 MARC (1833), pp. 366-367.

56 Como ha sintetizado Jan Goldstein, cl programa básico de la corriente "fisiológica" consistía en, por un lado, tratar la vida mental como una propiedad o manifestación de la materia física complejamente organizada que compone el cuerpo humano; por otro, en limitar el estudio de esto al fenómeno externamente observable; y, por último, en intentar construir una ciencia de la mente siguiendo el método baconiano. Esta corriente parecía ser monista a simple vista, pero en realidad cra algo más ambigua en sus planteamientos. El programa básico de la corriente "psicológica" estribaba, por cl contrario, en tratar a la mente como una realidad distinta de la del cuerpo, como una entidad radicalmente libre no sujeta a las leyes que prevalecen en el mundo físico y que sería propiamente investigable únicamente desde el interior, a través de la introspección. Esta segunda corriente esa así explicitamente dualista. GOLDSTEIN (1987), p. 243

57 MARC (1833), p. 364

58 Ese era el caso, por ejemplo, de Grand, N. (1826), Réfutation de la discussion médico-légale du Docteur Michu sur la monomanie homicide à propos du meurtre commis par Henriette Cornier, Paris. Otros médicos, como Urbain Coste, cuestionaron incluso la pretensión de los alienistas de que los médi- 
1824 jefe médico del asilo de Saint-Yon (Sena-Inferior), no sólo afirmaba en 1834 que la monomanía era una forma de enfermedad mental "mucho más rara de lo que se estaría inclinado a creer dadas las descripciones de los autores, sino que, si se examinaba a los alienados encerrados en los manicomios, el resultado era que no existía ni uno solo al que se le pudiera aplicar la etiqueta de monomaníaco ${ }^{59}$. Para él, cuando se atribuía a determinados enfermos tal rótulo lo que estaría pasando es que el diagnóstico estaría siendo realizado "sobre la palabra y no sobre la naturaleza", es decir, se habría descrito "esto que merecía el nombre de monomanía, pero de lo que no se encuentra ejemplo por así decirlo en la práctica"60. Desde su punto de vista, la locura afectaría simultáneamente a todas las facultades mentales, y sería en aquellas situaciones en que la intelectual, "sin quedar intacta", apareciera alterada "menos profundamente" que la afectiva y la volitiva, en las que se presentarían los casos de "pretendidos monomaníacos ${ }^{61}$ ". De este modo, la existencia de una monomanía homicida instintiva quedaba cuestionada por un modo de concebir la patología mental en el que a diferencia del que había hecho posible su surgimiento como entidad morbosa, no se admitía la posibilidad de una lesión aislada en una de las tres facultades mentales.

Así, pues, los alienistas continuaban teniendo problemas en la década de los años 1830 para hacer partícipe a la sociedad francesa del significado de la enfermedad mental que ellos estaban otorgando a ciertas conductas homicidas. A pesar de su esfuerzo por desarrollar la doctrina en el sentido de precisar mejor los rasgos semiológicos de la monomanía y su diagnóstico $0^{62}$, y aunque la admisión de esa entidad

cos debían ser los únicos competentes para pronunciarse sobre el estado mental de un acusado. COSTE, U. (1836), «Dictionnaire abregé des sciences médicales, tomes XI, XII et XIII». Reseña aparecida en: Journal Universel des sciences médicales, 43, 49-69, p. 53.

59 Foville, A. (1834), «Monomanie», Dictionnaire de Médecine et de Chirurgie pratiques, II, 508-510; p. 508

6) Ibidem.

61 Ibidem.

62 Tal vez el más relevante de ellos sea el de BAILLARGER, J.-G.-F. (1846), «Quelques considérations sur la monomanie», Annales médico-psychologiques, 8; 8-18, 157-169. Muchos autores escribían también mostrando sus estudios sobre casos concretos, tratando de incrementar el número de observaciones sobre la entidad morbosa con el objeto de contribuir a precisar mejor el cuadro semiológico de la misma. Algunos ejemplos notables de los mismos serían los siguientes: ESQUIROL (1840), «Observations médico-légales sur la monomanie homicide», Annales d'hygiène publique et de médecine légale, 23, 204-215; PEREIRA, A. (1845), «Discussion médico-légale sur la monomanie homicide invoquée comme moyen de défense dans le procès criminel de Blottin», Annales médico-psy'chologiques, 5, 41-73; AUBANEL (1849), «Mémoire médico-légale sur un cas de folie homicide méconnue par les assises du Var», Annales médico-psychologiques, I (2. ${ }^{\text {ser. }), ~ 80-123-123, ~ 245-297 ; ~ L U N I E R, ~ L . ~(1849), ~ " E x a m e n ~}$ médico-légale d'un cas de monomanie instinctive. Affaire du sergent Bertrand», Annales médicopsychologiques, l(2." ser.), 351-379. 
diagnóstica como eximente de responsabilidad fue siendo considerada de forma creciente en los tribunales, las dificultades para su aceptación general no habían cesado hacia $1850^{63}$. Esta ausencia de reconocimiento universal para la doctrina iba a ser uno de los factores más influyentes en el hecho de que los alienistas comenzaran a sentir la necesidad de acabar con una especie morbosa que, como era el caso de la monomanía homicida instintiva, empezaba a resultarles poco relevante, si es que no francamente molesta, para sus intereses ${ }^{64}$. Bariod, por ejemplo, finalizaba su tesis doctoral negando que pudiera ser admisible dicha forma de locura porque, entre otras razones, los hechos "malignos" que servían de base para establecer el diagnóstico de monomanía instintiva serían siempre el resultado, bien de concepciones delirantes, bien de un problema general, como la manía, bien de una debilidad congénita o adquirida, como la idiocia o la demencia ${ }^{65}$.

Los alienistas, por tanto, estaban planteando de nuevo la imposibilidad de que pudiera existir una enfermedad mental en la que la razón quedara conservada. En este sentido es tambien muy significativo el cambio de posición frente a la monomanía manifestado por uno de los más significativos alienistas del momento: Alexandre Brierre de Boismont (1797-1881). En una reseña a los Études cliniques (1852) de Bénedict-Agustin Morel (1809-1873), que era el médico jefe del asilo de alienados de Maréville y que empezaba a hacerse un hueco entre los más influyentes representantes de la psiquiatría francesa de la época, Brierre de Boismont indicaba que la obra tenía la "noble ambición" de "rehacer el edificio elevado por Pinel y Esquirol"66. En este sentido indicaba que "un punto importante" de la clasificación de Morel cra "el ataque dirigido contra la existencia de la monomanía"; un ataque que estaría basado en la opinión del autor de que "los casos de pretendida monomanía" no serían "más que casos de manía o melancolía incompletamente observados" pues no podría haber

6.3 Son numerosos los testimonios de los alienistas en ese sentido. Valga como ejemplo: LUNIER (1849), p. 350; AUBANEL (1849), pp. 81-82.

${ }_{64}$ Sobre el declinar del concepto de monomanía y su relación con el desarrollo de la profesión de psiquiatra en Francia puede verse GOLDSTEIN (1987), pp. 189-196.

65 BARIOD, J.-A. (1852), Études critiques sur les monomanies instinctives. Non existence de cette forme de maladie mentale, Paris: Thèse pour le doctorat en Médecine présentée et soutenue le 25 juin 1852, p. 48. Los otros argumentos eran: que los hechos en los que se apoyaba la doctrina no ofrecían "pruebas serias"; que los "hechos malignos de los alineados, actos que son la base de estas diversas monomanías, no son el resultado de la excitación morbida de una inclinación en medio de una inteligencia sana"; que "el hecho de un acto maligno no puede por él mismo bastar para constituir una especie de enfermedad mental"; que estos actos no tendrían "más que una importancia secundaria cn la sintimatología de la locura" por lo que el observador debería fijar el objetivo de sus observaciones "en el estado mental" en que dichos actos se producen.

Gr BRIERRE DE BOISMONT, A (1852), Reseña de «Études cliniques: Traité théorique et pratique des maladies mentales considérées dans leur nature, leur traitement, et dans leur rapport avec la médecine légale des aliénés, par M. MOREL, Paris, 1852», Annales Médico-psychologiques, 4, 609-621; p. 610. 
"locura localmente circunscrita y no manifestándose más que sobre un punto aislado"67. En su comentario Brierre de Boismont señalaba que admitía "como un hecho casi general la solidaridad de las facultades en el delirio parcial", por lo que sus "opiniones sobre la monomanía [eran] pues en el fondo semejantes a las de Morel". No obstante, a diferencia de éste, consideraba que "el momento [era] inoportuno para defender esta tesis" ya que

\footnotetext{
"las ideas verdaderas que tendía a propagar la doctrina de Esquirol están lejos de haber hecho su camino, y porque es de temer que los numerosos opositores que ha encontrado se apresuren a aprovechar esta disensión médica para hacer una nueva protesta airada. No se debería perder de vista, en las ciencias como en los negocios, este aforismo: 'Todo viene a punto a quien sabe esperar"68
}

Morel escribió una carta a Brierre de Boismont mostrándole que no compartía estos temores sobre los efectos de la desunión de los médicos, y lo argumentaba señalando las razones por las que consideraba que los jurisconsultos se habían situado en contra de los diagnósticos psiquiátricos:

"Están persuadidos [—razonaba Morel-] que miramos a voluntad al mismo individuo como alienado y razonable, un absurdo que nos atribuyen gratuitamente. Ahora bien, colocando de nuevo la cuestión sobre el terreno de la solidaridad de todas nuestras ideas, de todos los actos humanos, no destruimos la verdad del predominio de ciertas ideas y de ciertos actos escudriñamos sólo las cuestiones más a fondo, nos imponemos la obligación de los informes medico-legales de exponer de una manera más profunda los motivos que dirigen a los alienados, les damos una idea más completa"69

Morel mostraba que la idea de que las facultades mentales podían lesionarse aisladamente representaba un obstáculo, más que una ventaja, para que los diagnósticos forenses de los médicos fueran asumidos por los tribunales. La teoría de que determinados comportamientos homicidas eran ejecutados por personas en las que la inteligencia permanecía íntegra no terminaba de ser asumida por la sociedad francesa. ¿Por qué seguir, pues, defendiendo una posición cuya capacidad de extraer beneficios para los alienistas parecía haberse agotado? Para evitar las críticas y dar más solidez a sus afirmaciones bastaba con afirmar que la mente humana funciona de manera unitaria; que aunque una de sus funciones se presente como afectada de manera preponderante no por ello se debe pensar que el resto mantiene su integridad.

67 BRIERRE DE BOISMONT (1852), pp. 619-620.

68 BRIERRE DE BOISMONT (1852), p. 621.

(9) Ibidem. 
Muy pronto Brierre de Boismont iba a dar muestras de estar de acuerdo con estos argumentos.

En efecto, a penas un año más tarde, lcía una comunicación ante la Société médico-psychologique en la que se ocupaba de examinar "una de las proposiciones más controvertidas de la ciencia de las enfermedades mentales", la de "la monomanía o delirio limitado a un tema y dejando en el espíritu su integridad sobre los otros ${ }^{70}$. Manifestaba en él que, si bien los trabajos de Pinel y, sobre todo, de Esquirol habían sido "un gran progreso para su tiempo", aquél "no se podía detener", y se preguntaba si las doctrinas de estos autores estaban al nivel de los "conocimientos actuales ${ }^{71}$. Su trabajo representaba en realidad una defensa de la teoría de la doctrina de la solidaridad de las facultades mentales que le llevaba a establecer "una ley": la de la "unidad de las facultades intelectuales, afectivas y morales, solidaridad de sus funciones"72. La ventaja de adoptar esta posición era argumentada por Brierre de Boismont del siguiente modo:

\footnotetext{
"La doctrina de la unidad del espíritu y de la solidaridad de sus facultades bien establecida, no tiene sólo por resultado probar que la teoría ha ido demasiado lejos encerrando las locuras parciales en un rincón aislado del cerebro, mientras que en las otras partes conservaban su integridad; tiene también por consecuencia importante demostrar a los magistrados que el desorden de las facultades intelectuales y morales es raramente tan circunscrito como se había creido, y que la concepción delirante se cierne siempre sobre la cabeza del monomaníaco"73.
}

El texto anterior pone claramente de relieve que los cambios que se estaban operando en la nosografía francesa de mediados del siglo XIX no solo eran debidos al propio desarrollo interno de los saberes, sino que en esa transformación ejercía un influjo fundamental la necesidad de establecer un amplio grado de consenso social en relación con el significado que había que atribuir a determinadas conductas homicidas. En un momento en que los alienistas percibían que su aspiración a ser considerados como los únicos capacitados para determinar la situación mental de un individuo; en un instante en el que los juristas escribían libros dedicados a "demostrar la necesidad del concurso de la medicina en las decisiones de la magistratura sobre

70) Brierre de Boismont, A. (1853), «De l'ćtat des facultés dans les délires partiels ou monomanies, comuniqué à la Société médico-psychologique dans sa séance du 25 juillet 1853», Annales médicopsychologiques, 5, 576-591.

71 BRIERRE DE BOISMONT (1853), p. 568.

72 BRIERRE DE BOISMONT (1853), p. 578

7.3 BRIERRE DE BOISMONT (1853), pp. 589-590. 


\section{JOSÉ MARTÍNEZ PÉREZ}

todos los casos en que la locura puede ser sospechada"74, no parecía demasiado útil mantener una especie morbosa como la monomanía homicida instintiva. Mucho más cuanto que los magistrados apoyaban la idea de la unidad de las funciones mentales como base para explicar la patología mental ${ }^{75}$.

Brierre de Boismont presentó estas ideas en el marco del debate que sobre la monomanía estaba teniendo lugar en la Société médico-psychologique ${ }^{76}$. Sus puntos de vista no fueron, ni mucho menos, compartidos por la mayoría de los participantes en las discusiones. Casimir Pinel (m. 1856), por ejemplo, se mostró como un apasionado opositor de la teoría de la solidaridad de las facultades y como un firme partidario de responder afirmativamente a la pregunta sobre si existían realmente las monomanías. Además, manifestó que "combatir y destruir la idea" que este concepto llevaba aparejado, "sería llevar a la duda y a la incertidumbre" a los jueces, que estarían ya "muy poco dispuestos a reconocer la competencia de los médicos especiales ${ }^{77}$. No obstante, los defensores de las nuevas ideas no se amilanaron y sostuvieron con firmeza sus puntos de vista. Tal vez Morel fuera el más contundente en este sentido. No sólo iba a defender la solidaridad de las facultades mentales y a combatir la existencia de la monomanía instintiva, sino también a mostrar un nuevo camino para abordar el problema del diagnóstico médico-legal de las conductas homicidas. Para él, los actos designados por Esquirol y Marc bajo los nombres de monomanía de robo, incendiaria y homicida no serían más que "la consecuencia de una enfermedad principal que transtorna la razón ${ }^{78}$ ". Esa enfermedad principal no sería otra cosa que una modificación orgánica, sin la cual, Morel "no comprende la locura", por lo que, para él, en lugar de decir que en un individuo hay lesión de la voluntad, sería "más racional" decir que "la voluntad se ejerce con un instrumento enfermo" que no es otra cosa que el organismo alterado ${ }^{79}$. Así "atacando la teoría de la monomanía", Morel habría

74 VINGTRINIER (1852-53), «Des aliénés dans les prisions et devant la justice», Annales d'hygiéne publique et de médecine légale, 48 y 49; 369-396, 138-188. Vingtrinier se refería en concreto al folleto de Sacase - consejero en la corte de apelación de Amiens- titulado De la folie considérée dans ses rapports avec la capacité civile, publicado en París en 1851.

75 Brierre de Boismont señalaba que dicha doctrina había sido "desarrollada con verdadero talento por un magistrado eminente". BRIERRE DE BOISMONT (1853), p. 571.

76 Las discusiones, desarrolladas a lo largo de diez sesiones iniciadas el 20 de mayo de 1853 y concluidas el 26 de junio de 1854 , se pueden seguir a través de los resúmenes de las mismas firmados por Brierre de Boismont y publicados a lo largo de 1854 en las páginas de los Annales médicopsychologiques, 6, 99-118, 273-298, 464-474, 629-44. Sobre le papel de esta institución en la consolidación profesional de los alienistas puede examinarse: DowBIGGIN, I. (1989), «French psychiatry and the search for a professional identity: the Société Médico-psychologique, 1840-1870», Bulletin of the History of Medicine, 63, 331-355.

77 BRIERRE DE BOISMONT (1854), pp. 107-108.

78 BRIERRE DE BOISMONT (1854), p. 286.

79 BRIERRE DE BOISMONT (1854), p. 284. 
tenido "principalmente por objeto ofrecer a los médicos expertos un medio más racional, más médico, y consecuentemente más filosófico" para establecer sus peritajes": el de hacerlo sobre la base de "un problema de las funciones orgánicas"80. De este modo, una nueva y fructífera vía, cuyos resultados más notables iban a venir aparejados al desarrollo de la doctrina de la degeneración que el propio Morel iba a formular en 1857 en su Traité des dégénérescences, se abría a los médicos y alienistas para superar uno de los inconvenientes que la monomanía presentaba en la práctica forense: las dificultades para llegar a un diagnóstico suficientemente convincente acerca de su existencia como para que la irresponsabilidad del acusado quedara fuera de toda duda. En efecto, si como señalaba Lunier, para "conservar el terreno conquistado tan laboriosamente" por los psiquiatras no bastaba ya con "decir este hombre es un alienado", sino que era "preciso demostrarlo"81, una buena manera de hacerlo, de conceder a sus diagnósticos una certidumbre aparentemente mayor, era la de basar éstos en la existencia en los individuos de alteraciones orgánicas fácilmente constatables y no susceptibles de simulación ${ }^{82}$.

Así, pues, a la vista de lo anterior, parece evidente que uno de los factores que más influyeron en el rechazo de un buen número de alienistas frente a la monomanía homicida estuvo relacionado con las dificultades que encontraban en la práctica médico-forense y que estaba convirtiendo a esa entidad morbosa en una categoría diagnóstica molesta para quienes tenían que establecerla. Desde mi punto de vista, como intentaré mostrar a continuación, otra circunstancia que contribuyó también a hacer de la monomanía homicida una especie morbosa incómoda para los psiquiatras tuvo que ver con la posición en que les situaba cuando el diagnóstico médico legal tenía éxito y el alienado era enviado a un asilo.

80) BRIERRE DE BOISMONT (1854), pp. 583, 584-585.

81 LUNIER (1848), p. 351

82 Sobre esas dificultades puede verse VINGTRINIER (1952-53), pp. 371-373. Como hemos señalado en otro lugar, la teoría de la degeneración, al hacer depender el proceso patológico de una alteración somática suministraba signos supuestamente objetivos para el diagnóstico de las enfermedades mentales, lo que se mostraba muy útil de cara a la legitimación de los peritajes médico-forenses. HuERTAS, R.; MARTíneZ-PÉreZ, J. (1993), «Disease and crime in Spanish positivist psychiatry», History of psychicttry, 4, 459-481. 


\section{EL DESTINO DE LOS MONOMANÍACOS HOMICIDAS Y SU INFLUJO SOBRE LA SUERTE DE UNA ESPECIE MORBOSA.}

La ley sobre los alienados de 1838 , que ha sido considerada como el "paso decisivo en el surgimiento de una profesión 'psiquiátrica' en Francia"83, rescrvaba a los alienistas un papel central dentro de las pautas que debían seguirse para la admisión y puesta en libertad de los enfermos mentales en los manicomios. Una de las normas que establecía en este sentido era, como indicaba Aubanel-el médico en jefe del asilo de Marsella-, la de que todo alienado había de ser puesto en libertad cuando el médico declarara su curación ${ }^{84}$. Este hecho estaba generando una cierta inquietud entre los médicos, pues hacía recaer sobre ellos la decisión de la puesta en libertad de cierto tipo de enfermos que, al ser dados de alta, mostraban, como cra el caso de los monomaníacos, recaídas ${ }^{85}$. Es fácil comprender que unos profesionales que estaban siendo acusados por los magistrados de estar atacando "los derechos de la sociedad" por diagnosticar como una forma de enfermedad mental determinadas conductas homicidas $^{86}$, no se mostraran muy propensos a tener que lidiar también con la acusación de que estaban dejando en libertad individuos capaces de volver a manifestar su comportamiento criminal. Aubanel, por ejemplo, consideraba "muy legítimo" el temor de un juez que, entre las preguntas que le formuló durante un proceso en el que había emitido un diagnóstico de monomanía homicida instintiva, figuraba la de que si no sería posible que una vez que el procesado fuera curado y devuelto a la sociedad volviera de nuevo a matar ${ }^{87}$. Considerando que esa posibilidad representaba "una laguna" que era necesario llenar "en interés de la seguridad pública"88, el psiquiatra se decantaba por una fórmula favorable para todos menos para el enfermo mental: la de considerar que el encierro de los alienados homicidas debería ser "perpetuo". Para él, en efecto,

8.3 GoldSTEIN (1987), p. 276. Según expone esta autora ello se debió a que integró a la nueva especialidad en el aparato del Estado al establecer una red de asilos con un equipo de médicos a tiempo completo, que constituyeron una especie de funcionarios psiquiatras.

84 AubANEL (1846), «Rapports judiciares et considérations médico-légales sur quelques cas de floie homicide», Annales d'hygiène publique et de médecine légale, 36, 163-214, 403-439; p. 188.

8.5 Brierre de Boismont señalaba que al obtener "su libertad" los monomaníacos mostraban de nuevo su comportamiento extravagante. BRIERRE DE BOISMONT (1846), «De la nécessité de créer un établissement spécial pour les aliénés vagabonds et criminels», Annales d'hygiène publique et de médecine légale, 35, 396-412; p. 397.

86 AUBANEL (1846), p. 164.

87 Aubanel (1846), p. 187.

88 AubANEL (1846), p. 188. 


\begin{abstract}
"El médico legista cubre un gran deber de humanidad preservando al monomaníaco de la infamia, salvándole de la mano del verdugo; pero el médico de los alienados desconocería los deberes sagrados de la sociedad exponiendo de nuevo a ésta a sus ataques por una salida intempestiva. Todo alienado homicida, lo digo por última vez, debe ser encerrado para siempre jamás en una casa de alienados"89
\end{abstract}

No obstante, dejaba bien claro cual era su verdadera preocupación: la de eludir una tarea que no les resultaba nada grata. Sería "de desear" — decía_ que la legislación fuera modificada sobre este punto, que viniera " a descargar, en una palabra, a los médicos de la grave responsabilidad que pesa sobre ellos en estos casos"90. Abogaba por ello a favor de una ley que obligara a que, aun siendo establecida la curación, este tipo de pacientes permaneciera encerrado a perpetuidad ${ }^{91}$.

Esta contradictoria posición frente a las obligaciones a las que les conducía su ya alcanzado status de expertos en el fenómeno de la locura, ese afán por reclamar un lugar destacado en los peritajes ante los tribunales pero al mismo tiempo por rehuir sus responsabilidades como médicos de los asilos, es indudable que venía dado por el temor a ser acusados de ser un grupo de profesionales que atentaban contra la seguridad pública al librar del cadalso, primero, y poner en libertad, después, a individuos peligrosos. La monomanía les situaba así en una posición incómoda. No debe pues extrañar que muchos alienistas contemplaran con una sensación de alivio la desaparición de esta especie morbosa de las clasificaciones de las enfermedades mentales, y que se mostraran satisfechos con la ausencia en las mismas de una entidad que, por lo demás, se había mostrado muy útil para el desarrollo del conocimiento y de la práctica psiquiátricos.

\title{
7. A MODO DE CONCLUSIÓN
}

El examen de la posición que, dentro de su pensamiento nosológico, concedieron los alienistas franceses de la primera mitad del siglo XIX a una categoría diagnóstica como la monomanía homicida instintiva, resulta por tanto de gran ayuda para poner de relieve algunos de los factores que inciden sobre el proceso destinado a ordenar la

89) Aubanel (1846), p. 189.

90) Ibidem.

9) Aubanel (1846), p. 437. En esta misma línea, Brierre de Boismont solicitaba que, para la "seguridad de la sociedad", los alienados criminales permanecieran encerrados durante el tiempo que duraría la pena en caso de haber sido hallados culpables. BRIERRE DE BOISMONT (1846), p. 411. Más tarde radicalizó su posición y afirmó la necesidad de "mantener siempre el secuestro para todos los locos peligrosos". BRIERRE DE BOISMONT (1853), «De la monomanie ou délire partiel au point de vue médicolégale», Annales d'hygiène publique et de médecine légale, 49, 382-395; p. 394. 
diversidad del comportamiento humano. En concreto, se muestra muy útil de cara a indagar en los mecanismos por los que un determinado tipo de conducta aberrante se ve sometida a cambios en su adscripción a una clase u otra de desviación. El surgimiento y progresivo abandono de esa entidad morbosa por parte de los alienistas franceses muestra, en efecto, cómo la adscripción del significado de enfermedad mental a un tipo de comportamiento homicida se vio condicionada por una serie de elementos que se nos presentan como estrechamente relacionados entre sí. En efecto, los cambios tanto en las teorías científicas y filosóficas, como en los objetivos profesionales de quienes estaban procediendo a clasificar esas conductas, y el grado de consenso social que fueron capaces de alcanzar para los significados que atribuían a esos comportamientos, se muestran como los factores principales que, influyéndose mutuamente, contribuyeron a determinar la aparición y el eclipse de esa relevante especie morbosa que fue la monomanía homicida instintiva. 